\title{
The Head of the Chinese Adjectives and ABB Reduplication
}

\author{
WANG Zhi-jun \\ University of Massachusetts Amherst, Amherst, USA
}

\begin{abstract}
This study investigates whether the head of the Chinese adjective compounds is on the left or right or on both sides. Using the ABB type of adjectives as evidence, the author argues that the head of the Chinese adjectives is more likely on the left than on the right. This study supports the Headedness Principle and also calls into question whether a suffix is the head of a word as traditionally assumed in morphology. On the other hand, it also provides evidence that reduplication is a compounding process as Haugen (2008) has claimed since most of the reduplicated constituents of $\mathrm{ABB}$ have a specific lexical meaning and many of them can be used as independent words.
\end{abstract}

Keywords: adjective, head, compound, ABB reduplication, reanalysis, infix, suffixation, gestalt word

\section{Introduction}

Compounding is a major and productive means of word formation in Chinese (Ceccagno \& Basciano, 2007; Sproat, 1998). Although there is a significant difference between Chinese and English in terms of what forms a compound (in English, compounds should be composed of two or more words), Chinese linguists basically consider any polysyllabic units as compounds if each constituent has its lexical meaning with certain word properties, and these constituents may be a morpheme, not a word, and cannot be used independently (LI \& Thompson, 1981; Starosta, Kuiper, Ng, \& WU, 1998). This study will take the same approach in defining compounding in Chinese. However, it is a debate on where the head is located in a Chinese compound.

Williams (1981) and Lieber $(1981,1992)$ claimed that all the compounds have their heads on the right in English no matter if they are nouns, verbs, or adjectives. Chinese is very different from English in this regard. HUANG (1998) proposed that verbs have their heads on the left and adjectives are headless; thus Chinese is basically a headless language. Starosta et al. (1998) and Ceccagno and Basciano $(2006,2007)$ argued that generally Chinese compound words are right-headed including adjective compounds. Sproat (1998) also argued that in a traditional sense, the adjectives are right-headed and verbs are left-headed. In addition, Packard (2000) proposed a Headedness Principle for Chinese compounds. According to the Headedness Principle, noun words have nominal constituents on the right as their heads and verb words have verbal constituents on the left as their heads; other word types are left relatively free to vary.

This paper will argue that if Chinese adjectives are a type of verbs, as many have claimed (CHAO, 1968; McCawley, 1992) because they share syntactic properties, then they might also share the morphological properties. We would expect that they should at least share some major morphological properties; particularly,

WANG Zhi-jun, assistant professor, Ph.D., Department of Languages, Literatures and Cultures, University of Massachusetts Amherst. 
they should have their heads on the left side of adjectives. The ABB type of Chinese adjectives such as 白茫茫 baimangmang (a vast expanse of whiteness) and 直挺挺 zhitingting (straight and stiff) and word reduplication suggest that adjectives are consistently on the left of the words, thus the head of an adjective compound is on the left. This paper also proposes that the ABB type of adjectives should be treated as compounds, because most of the $\mathrm{BB}$ constituents in the compounds are not suffixes and have lexical meanings, although some of them start to lose their concrete meaning and are in the process of grammaticalization.

\section{The "Head" Debate}

The Headedness Principle posits that noun words have nominal constituents on the right and verb words have verbal constituents on the left. Other word types are left relatively free to vary. This principle is based on the statistical results of the Chinese adjective formation. According to Packard (2000), 90\% of all Chinese nouns have a noun on the left and $85 \%$ of all verbs have a verb on the left:

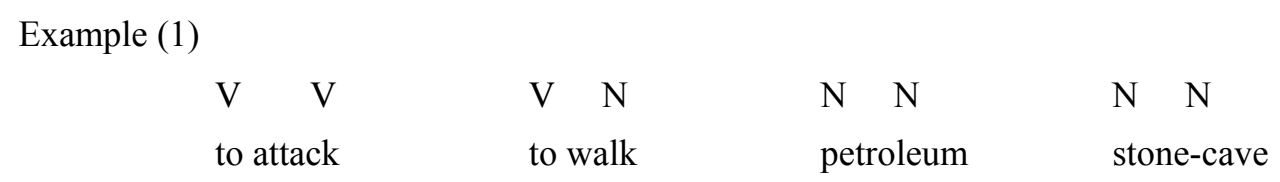

As shown in Example (1), the first two words are verb compounds; they both have verbs on the left; while the noun compounds have nouns on the right in the latter cases.

However, Packard (2000) did not give any specific statistic numbers about adjectives, and indicated that the head of adjectives (counted as other types of words) are free to vary. Ceccagno and Basciano (2006) criticized Packard's Headedness Principle and argued that the Headedness Principle will not adequately describe some of the adjective compounds such as coordinate compounds, attributive verbal compounds, and attributive adjectival compounds, because these compounds either have their heads on the right or on both sides, but not on the left as posited by the Headedness Principle. The following examples in Table 1 are from Ceccagno and Basciano (2006).

Table 1

Compounds Exceptions to the Headedness Principle

\begin{tabular}{|l|l|l|l|l|l|l|}
\hline Script & Compound & Cat. & Structure & Class & Head & Gloss \\
\hline 店铺 & dianpu & N & {$[\mathrm{N}+\mathrm{N}]$} & CRD & B & shop + shop = shop \\
\hline 爱恋 & ailian & V & {$[\mathrm{V}+\mathrm{V}]$} & CRD & B & (to) love + (to) love = (to) love \\
\hline 美丽 & meili & A & {$[\mathrm{A}+\mathrm{A}]$} & CRD & B & beautiful + beautiful = beautiful \\
\hline 口算 & kousuan & V & {$[\mathrm{N}+\mathrm{V}]$} & ATT & R & mouth + (to) calculate $=$ (to) do a sum orally \\
\hline 云集 & yunji & V & {$[\mathrm{N}+\mathrm{V}]$} & ATT & R & cloud + (to) gather $=($ to) come together in crowds \\
\hline 笔直 & bizhi & A & {$[\mathrm{N}+\mathrm{A}]$} & ATT & R & tool for writing and drawing + straight $=$ straight as ramrod \\
\hline 冰凉 & bingliang & A & {$[\mathrm{N}+\mathrm{A}]$} & ATT & R & ice + cold $=$ ice-cold \\
\hline
\end{tabular}

Notes. $\mathrm{N}$ = Noun; $\mathrm{V}=$ Verb; $\mathrm{A}$ = Adjective; $\mathrm{R}=$ Right; $\mathrm{B}=$ Both; $\mathrm{CRD}=$ Coordinate; $\mathrm{ATT}=$ Attributive.

These examples clearly are not covered by the Headedness Principle; however, the Headedness Principle is based on the statistical results of all types of nouns and verbs, so we would assume that these types of exceptions would have been counted in the statistics by Packard; in other words, these types of compounds are not so many in Chinese and do not influence the statistical results. 
HUANG (1998) argued that Chinese is a headless language in morphology, because the category type of a compound cannot be determined by the rightmost member or leftmost member of a compound. He claimed that noun compounds are more right-headed; verb compounds are more left-headed and adjective compounds have no particular tendency toward either the rightmost or the rightmost member of a compound. As a result, Chinese compounds in general are headless. He examined the entire dictionary of GRC (Guoyu Ribao Cidian Mandarin Daily Dictionary) (1993) and found 24,000 disyllabic compounds (including all adjectives). His survey showed that "neither the rightmost member nor the leftmost of a compound can claim to monopolize the privileged status of determining the category of a compound" (HUANG, 1998, p. 261).

The author of this paper disagrees with HUANG in that no matter whether it is left-headed or right-headed or on both sides, Chinese words indeed have heads. We cannot say Chinese is a headless language just because the head does not have a unitary position in adjective words.

Modeling CHAO's adjective classification, the author used the following criteria to determine the form class of adjectives: Adjectives (1) can be negated by 不 bu "not"; (2) can function as predicates; (3) can take 著 zhe, 了 le, and 过 guo; and (4) can have “ $\mathrm{X}$ ” 不 “ $\mathrm{X}$ ” form such as 好不好 haobuhao "good or not”. The author examined all the disyllabic adjective compounds in 现代汉语词典 xiandaihanyucidian (MCD (Modern Chinese Dictionary)) (2002) and found that 2,165 out of 2,875 adjectives have adjectives on the left side; this counts for $75 \%$ of disyllabic adjective compounds. Interestingly, the author also found that 2,070 of 2,875 disyllabic adjective words have adjectives on the right. This counts for $72 \%$ of total adjective compounds. $62.3 \%$ of adjective compounds (1,792 in total) have adjective constituents on both sides. The reason is that most adjectives of this type are composed of two synonyms or antonyms.

Table 2 is a comparison between the author's statistics numbers of disyllabic adjective compounds in $M C D$ (2002) and HUANG's number in GRC (1993).

Table 2

Comparison Between the Numbers of Disyllabic Compounds in GRC and MCD

\begin{tabular}{|c|c|c|c|c|c|c|c|c|c|c|c|c|}
\hline & AA & AV & AN & $\mathrm{AX}^{*}$ & VA & NA & VV & $\mathrm{NN}$ & $\mathrm{N}$ & $\mathrm{VN}$ & $\mathrm{XX}$ & Total \\
\hline GRC & 1,609 & 173 & 198 & & $?$ & 209 & 103 & 90 & 72 & 378 & 66 & 2,898 \\
\hline MCD & 1,792 & 171 & 128 & 74 & 90 & 188 & 78 & 86 & 52 & 185 & 31 & 2,875 \\
\hline
\end{tabular}

Notes. $\mathrm{X}$ in $[\mathrm{AX}]$ indicates suffixes; [XX] type includes [Adverb N], [Adv V], [Adv A], and [Numeral N]; * indicates that there is no AX category in GRC.

HUANG's claim might be true as far as adjectives are concerned. The total number of disyllabic adjectives is 2,898, and 1,609 of them are [A + A] type, which accounts for $55.5 \%$ of all adjective compounds. Using his numbers, the author gave further computation, and found that there are 1,818 adjectives having adjectives on the right side, accounting for $62.7 \%$ of total adjective compounds; 1,980 adjectives have an adjective on the left side of a compound and account for $68.3 \%$ of all adjective compounds. This result is basically consistent with the author's statistics: Neither a leftmost member nor rightmost member of a compound can dominate the other. The differences between the author's numbers and HUANG's might be caused by different criteria, intuition, and judgment on the form class identity of adjectives, verbs, or nouns. HUANG did not give his criteria on which the adjectives are identified. In addition, the author of this paper has counted all the adjectives marked by “书” ("written language") in the MCD. These adjectives are rarely used and closer to classical Chinese, and most of 
them are $[\mathrm{A}+\mathrm{A}]$ type adjectives. These additions increase the number of $[\mathrm{A}+\mathrm{A}]$ type significantly. HUANG's dictionary is more a spoken Chinese dictionary than a written Chinese dictionary.

No matter how different the two statistics might be, the same finding is made: There seems to be no fixed head position in adjectives. The reason is that there is a large proportion of adjectives having adjective constituents on both sides and most of them are synonyms and antonyms; in other words, they are all coordinate adjectives. The author's statistic is $62.3 \%$ and HUANG's is $55.5 \%$. We simply cannot tell which side is preferred as the position of the head for adjective compounds. However, it is still an overstatement that Chinese compounds have no heads. Clearly, Chinese nouns have their heads on the right and Chinese verbs have their heads on the left (Packard, 2000). The only question is whether Chinese adjectives are left-headed or right-headed as Chinese verbs are. Moreover, even if the compound words have the same class of the word constituents on each side, how they (the left constituent and right constituent) behave morphologically and syntactically can offer more information about the headedness of those compound words. The ABB reduplication and syntactic reanalysis are the two examples the author examined in this paper.

\section{The ABB Reduplication and the Head of the Adjectives}

Although we cannot determine whether the heads of adjectives are on the left side or right side of the words in compounding, in the $\mathrm{ABB}$ adjective reduplication process, there is evidence that supports that the heads of Chinese adjectives are on the left hand sides of Chinese adjective words. We call this proposal as "Left-Headed Hypothesis".

According to CAO (1995), there are 338 ABB adjectives in Chinese. Similarly, the author of this paper finds 336 ABB adjectives in MCD and 现代汉语八百词 xiandaihanyubabaici (Modern Chinese 800 Words, LV, 1996), 293 out of 336 adjectives have adjectives on the left, and it is $87 \%$ of total ABB adjectives. Does this suggest that the ABB adjectives have their heads on the left? Before we answer this question, let us first look at Table 3, which illustrates the typical ABB adjective reduplication.

Table 3

ABB Reduplication

\begin{tabular}{|l|l|l|}
\hline $\mathrm{A}+\mathrm{BB}$ & $\mathrm{N}+\mathrm{BB}$ & $\mathrm{V}+\mathrm{BB}$ \\
\hline 矮墩墩 (aidundun, short) & 水灵灵 (shuilingling, charming) & 笑眯眯 (xiaomimi, smiley) \\
\hline 辣酥酥 (lasusu, spicy) & 气鼓鼓 (qigugu, angry) & 颤巍巍 (chanweiwei, shaky) \\
\hline 懒洋洋 (lanyangyang, lazy) & 泪汪汪 (leiwangwang, teary) & 喘吁吁 (chuanxuxu, breathless) \\
\hline 空荡荡 (kongdangdang, empty) & 汗津津 (hanjinjin, sweaty) & 醉醺醺 (zuixunxun, drunk) \\
\hline
\end{tabular}

As shown in Table 3, there are three types of lexical categories on the left for ABB adjectives. The word stems can be an adjective, a noun, or a verb, but the reduplicated part is always an adjective, so does this mean that BB is the head since it determines the category of the whole word? The problem is that it is very hard to determine the word class of BB. Some of them are adjectives, because they are used freely as an adjective, and others cannot be used freely and their original words are not adjectives. For example, 茫茫 mangmang "vast expanse" in 白茫茫 baimangmang “a vast expanse of whiteness" can be used in 茫茫的大海 mangmang de dahai “the vast ocean", but we cannot say 醺醺的爸爸 xunxun de baba “drunk father" or 醺醺地醉 xunxun de zui "drunk", thus we cannot determine the form class of 踵踵 xunxun “drunk". One approach to this question is 
to treat $\mathrm{BB}$ as a suffix, and the suffix functions as a head and determines the category of the whole word. This will suggest that the head of ABB adjectives is on the right. However, if we further examine the ABB adjectives, we will find the $\mathrm{ABB}$ reduplication includes two types of morphological processes: One is compounding and the other is suffixation. The author will argue that most ABB adjectives are compounds and only a minority of ABB adjectives is derivational and has suffixation. The reasons are as follows:

(1) Most BBs still have concrete lexical meanings and only a few BBs such as 乎乎 huhu and 巴巴 $b a b a$ can be considered as suffixes since they have lost their lexical meanings. Some others may be in the process of losing their lexical meanings and are becoming suffixes. According to the author's calculation, $91 \%$ of ABB adjectives are compounds and only $9 \%$ of $\mathrm{ABB}$ adjectives are derivational words with suffixes such as 平平 huhu and 巴巴 baba, which will change a word into an adjective.

(2) Most BBs can only be attached to a very limited number of words or bound roots while a suffix should be very productive and can be attached to a variety of different words, thus we can conclude that most BBs are not suffixes and they should be treated as compounds, because BBs still contribute to the meanings of the whole words. ZHANG (2005) argued that some BBs can only be attached to one adjective such as 漆漆 qiqi "paint" only combine with 黑 hei “dark, black”, 皚皚 aiai “pure white” can only combine with 白 bai “white”.

(3) Many BBs can be used freely as a word such as (白) 茫茫 (bai) mangmang in 茫茫的大海 mangmang de dahai “vast expanse of the ocean”, (静) 悄悄 (jing) qiaoqiao in 春天悄悄地来了 chuntian qiaoqiao de lai le "Spring has come quietly", and (亮) 闪闪 (liang) shanshan "flahsing/shining" in 闪闪的 红星 shanshan de hongxing "flashing/shining red star".

(4) If the head is the suffix on the right of the adjective, we cannot explain the suffixation in which the reduplicated morpheme does not have its original form (see Example (2)):

$\begin{array}{rllll}\text { Example (2) 甜丝丝 } & \text { 凉丝丝 } & \text { 蓝盈盈 } & \text { 乱糟糟 } & \text { 兴冲冲 } \\ \text { tian sisi } & \text { liang sisi } & \text { lan yingying } & \text { luan zaozao } & \text { xing chongchong } \\ \text { sweet } & \text { cold } & \text { blue } & \text { messy } & \text { happy }\end{array}$

There are no such words as “甜丝 tiansi”, “凉丝 liangsi”, “蓝盈 lanying”, “乱糟 luanzao”, and “兴冲 xingchong", and the right constituents cannot be a head; thus it is impossible to reduplicate the head if the suffixation is a head operation as traditionally assumed; in other words, the reduplication here is not a head operation on the right. We can only assume that the reduplicated morpheme BB here is a single morpheme or a disyllabic morpheme that is attached to the left constituent of the adjective. If the BB part has a lexical meaning, then the $\mathrm{ABB}$ reduplication is more likely a compounding process than a suffixation. Sometimes, it just reduplicates the second constituent of the word; other times, it just reduplicates a non-constituent and attaches it to the head. In short, the reduplication itself is a kind of compounding construction (Haugen, 2008). Table 4 shows the compounding process.

Table 4

ABB Reduplication in Chinese

\begin{tabular}{|l|l|l|l|l|l|}
\hline & Type & Adj. & Pinyin & Structure & Gloss \\
\hline Type 1 & A + BB & 矮墩墩 & aidundun & 矮 + 墩墩 & short \\
\hline Type 2 & AB + B & 赤裸裸 & chiluoluo & 赤 + 裸 + 裸 & naked; undisguised \\
\hline Type 3 & BA + B & 香喷喷 & xiangpenpen & 香 + 喷喷 & delicious \\
\hline
\end{tabular}


In Type $1, \mathrm{BB}$ as a whole is attached to the left constituent and in Type 2, the right constituent B is reduplicated first and then attached to the left side. Type 3 is actually a two-step reduplication: First step, it is the reduplication on the left morpheme-BBA. Second step, BBA switches positions, A goes to the left side and BB goes to the right, as shown in Table 5.

Table 5

BAB Reduplication Process

\begin{tabular}{|c|c|c|c|}
\hline Compound & Step 1 & Step 2 & Pinyin \\
\hline 喷香 & *喷喷香 & 香喷喷 & xiangpenpen, delicious \\
\hline 通红 & *通通红 & 红通通 & hongtongtong, red \\
\hline 油绿 & *油油绿 & 绿油油 & lvyouyou, green \\
\hline 慜白 & *慜慜白 & 白慜慜 & baishasha, pale \\
\hline 冰冷 & *冰冰冷 & 冷冰冰 & lengbingbing, cold \\
\hline 绵软 & *绵绵软 & 软绵绵 & ruanmianmian, soft \\
\hline 纷乱 & *纷纷乱 & 乱纷纷 & luanfenfen, chaotic \\
\hline 幽静 & *幽幽静 & 静幽幽 & jingyouyou, quiet \\
\hline
\end{tabular}

Note. * indicates that there are no such compound words in Mandarin Chinese.

Note that $\mathrm{AB}$ is not likely to switch positions before the reduplication takes place as there is no motivation to do that. For example, it is not possible to have this type of process in ABB reduplication such as in 通红 $\rightarrow$ 红通 $\rightarrow$ 红通通 hongtongtong “red". The fact that Shanghai dialect has Step 2 form of the reduplication suggests that our proposal is correct. In Shanghai dialect, the reduplication is not ABB, it is BBA such as 喷喷香 penpenxiang “delicious”, 通通红 tongtonghong “red”, 冰冰冷 bingbingleng “ice-cold”, etc.. This shows that the reduplication rules are different among Chinese dialects, thus the head positions are different from those of Mandarin Chinese too.

As seen above, the head of ABB adjectives is always on the left. If it is originally on the right, it should go back to the left after the reduplication operation. This is strong evidence supporting the Left-Headed Hypothesis.

As for the ABB suffixation such as 干巴巴 ganbaba “dry”, 湿乎乎 shihuhu “wet”, 巴巴 baba and 乎 乎 $h u h u$ have lost their lexical meanings and do not contribute to the meanings of the whole words, so they should be treated as suffixes. However, it is very important to note that an adjective constituent in adjective gestalt word is always the virtual head if the adjective constituent is present and suffixation is not necessarily a head operation if the reduplicative suffix does not change category of the word form class (Lieber, 1992; Marantz, 1982; McCarthy \& Prince, 1986). If we look at the ABB adjectives with 巴巴 $b a b a$ and 平平 $h u h u$ as suffixes, there is only one case in 血乎平 $x u e h u h u$ "bloody" that 平平 $h u h u$ changes the form class of the word: 血 $x u e$ "blood" is a noun. This clearly indicates that the suffixes such as 巴巴 $b a b a$ and 平平 $h u h u$ do not change the form class of the whole word, thus it should not be treated as the head. We define the head as: (1) Head percolates its morphosyntactic features onto the rest of the compound; (2) Head determines the properties and the grammatical category of the whole compound; and (3) Head is the only obligatory element of a constituent. 
According to this definition, 巴巴 $b a b a$ and 乎平 huhu mostly do not percolate their morphosyntactic features onto the rest of the compound and do not determine the form class of the whole word and are not the only obligatory element of a word, thus they are not the heads of ABB adjectives. A suffix is a head only if it can change the lexical category of the word base, or if it does not change the lexical category but it changes the syntactic feature of the base (Scalise, 1988).

\section{Other Evidence Supporting Left-Headed Hypothesis}

\section{Reanalysis}

Packard (2000) proposed that the identity of morphemic constituents is mainly word-driven and the form class identities of its constituents are generally determined by the form class identity of the word. In other words, the word identity determines the identity of the word head. This morphological process is called reanalysis or percolation. Let us look at the two reanalysis examples: 石雕 shidiao "stone-carving" and 大便 dabian "to move the bowels".

石雕 shidiao “stone-carving" is a noun, but it has a verb 雕 diao “carve" on the right, and there are also other words with 雕 diao on their right sides such as 牙雕 yadiao "ivory carving", 漆雕 qidiao "carved lapuer-ware", 浮雕 fudiao “relief sculpture", and 贝雕 beidiao "shell carving", Packard (2000) argued that the productive use of 雕 diao "carve" as a noun suggests that 雕 diao has undergone a reanalysis process that change its form class from verb into noun. The gestalt word dominates over its internal constituents and the word identity determines the identity of the head. 雕 diao "carve" is a verb, but it is on the right side of the noun word, thus it is reanalyzed as a noun.

This reanalysis is also applied to verbs such as 大便 dabian "to move the bowels", 小便 xiaobian "to urinate". Clearly, both 大 da "big" and 小 xiao "small" are adjectives, but because they occupy the left-hand side of gestalt $[\mathrm{A}+\mathrm{N}]$ verbs, and left side is the head position for verbs, therefore, they are reanalyzed as verbs, as shown in Example (3):
Example (3) (a) 我大完便就去打球。
wo da wan bian jiu qu da qiu
I big finish convenience then go play ball
I will go to play ball after "moving the bowels".
(b) 他小了三十分钟的便。
ta xiao le san shi fen zhong de bian
He small LE 30 minute DE convenience
He peed for 30 minutes.

This kind of use for compound words is a reflection of native speakers' intuitive morphological knowledge about Chinese compounds. Packard's observation is based on verb and noun disyllabic compounds, and these compounds clearly have heads within the gestalt words, in which a verb has its head on its left side and a noun has its head on its right side. Because native Chinese speakers know that a verb tends to have its head on the left and a noun tends to have its head on the right, they will construe the left constituent of any verb as the head of the verb and right constituent of any noun as the head of the noun. So Chinese speakers can accept the fact that 大 $d a$ “big”, 小 xiao “small”, 雕 diao “carve" in 石雕 shidiao 
“stone-carving", and 大便 dabian "to move the bowels" 小便 xiaobian "to pee" have changed their form classes due to the percolation of form class of the gestalt word (Packard, 2000). Interestingly, this reanalysis process is also applied to adjectives, especially the ABB adjectives. Table 6 shows the ABB adjectives reanalysis process.

Table 6

Adjective Reanalysis Examples

\begin{tabular}{|l|l|l|l|}
\hline $\mathrm{N}+\mathrm{BB}$ & Pinyin and meaning of the adjectives & Reanalysis examples & Gloss of the sentences \\
\hline 肉墩墩 & roudundun, fat & 这个人真肉。 & The person is very fat/very slow. \\
\hline 牛哄哄 & niuhonghong, cocky & 这位老板很牛。 & The boss is excellent. \\
\hline 油汪汪 & youwangwang, oily & 这张桌子太油了。 & The table is too greasy. \\
\hline 气鼓鼓 & qigugu, angry & 她对这件事很气。 & She is very angry with this. \\
\hline \multirow{2}{*}{ 水淋淋 } & shuilinlin, watery & 今天买的猪肉太水了。 & There is too much water in the pork. \\
\cline { 2 - 4 } & 这篇文章太水了。 & This paper is too weak. \\
\hline 毒花花 & duhuahua, scorching & 今天的太阳太毒了。 & The sun is scorching. \\
\hline 火辣辣 & huolala, hot & 这位演员终于火了。 & The actor is popular finally. \\
\hline 木呆呆 & mudaidai, stonily & 她的男朋友很木。 & Her boyfriend is very slow (stonily). \\
\hline 文绉绉 & wenzhouzhou, genteel & 姚明很文, 但那没有用。 & Yao Ming is very gracious, but it is useless. \\
\hline 贼溜溜 & zeiliuliu, sneaky & 车上的小偷太贼了。 & The thief on the car is very sneaky. \\
\hline 面乎乎 & mianhuhu, weak & 有的男人做事很面。 & Some men are very weak in doing things. \\
\hline
\end{tabular}

As we can see in Table 6, the heads on the left-hand sides in the ABB adjectives are all nouns; however, they can be used as adjectives through reanalysis. The reason can be that they occupy the left-hand side of the adjective compounds, and the left-hand side is the head position for Chinese adjectives; therefore, they are changed into adjectives. Again this supports the author's Left-Headed Hypothesis for Chinese adjectives.

In addition, this form class percolation can be applied to other Chinese adjectives such as attributive adjectival compounds and adjectives with infixes. This is shown in Table 7.

Table 7

Reanalysis in Other Adjectives

\begin{tabular}{|l|l|l|l|}
\hline $\mathrm{N}+\mathrm{A}$ & Examples & Pinyin and meaning of the adjectives & Gloss of the sentences \\
\hline 冰凉 & 他的手很冰。 & bingliang, ice-cold & His hand is ice-cold. \\
\hline $\mathrm{N}+$ 里不 $+\mathrm{NA}$ & & & \\
\hline 土里土气 & 这位教授太土了。 & tulituqi, corny & The professor is too corny. \\
\hline
\end{tabular}

冰 bing "ice" and 土 $t u$ "dust, soil" are nouns, but here they are used as adjectives because they are on the left side of the words. Table 7 further shows us that the reanalysis and percolation is a wide spread phenomenon in Chinese morphology, especially in Chinese adjectives.

\section{Adjective Infixes}

The Chinese adjectives with infixes also show the same tendency in adjective formation. The author found 58 of them in MCD, and 54 out of 58 adjectives have the adjective on the left, which accounts for $91 \%$ of the adjectives; only four of them have a noun on the left. We cannot say that the infix is the head of this type of adjectives. The head is clearly on the left side of the word. Table 8 shows some of the examples. 
Table 8

Adjectives With Infixes

\begin{tabular}{|l|l|l|}
\hline $\mathrm{A}+\mathrm{B}+(\mathrm{C}+\mathrm{D})$ & Pinyin & Gloss \\
\hline 白不呲咧 & baibucilie & white \\
\hline 黑不溜秋 & heibuliuqiu & dark, black \\
\hline 花不棱登 & huabulengdeng & multicolored \\
\hline 滑不唧溜 & huabujiliu & slippery \\
\hline 酸不溜丢 & suanbuliudiu & sour \\
\hline 老实巴交 & laoshibajiao & honest \\
\hline 胖不伦敦 & pangbulundun & fat \\
\hline 黑咕隆咚 & heigulongdong & dark \\
\hline 曲里拐弯 & quliguaiwan & bent, crooked \\
\hline 笨了呱吹 & benleguaji & silly, stupid \\
\hline 糊里糊涂 & hulihutu & confused \\
\hline 怪里怪气 & guailiguaiqi & weird, strange \\
\hline 冷不丁 & lengbuding & sudden \\
\hline 软古囊 & ruangunang & soft \\
\hline
\end{tabular}

ZHU (1994) treated B such as 不 bu "not" and 里 li "inside" in these adjectives as infixes, because they are comparatively free and can form quite a few adjectives. He argued that B $+(C+D)$ is not a suffix, because B is independently used. The author thinks it is a better treatment than suffix.

\section{A-not-A Question Operation on Adjective Compounds}

As many have claimed (CHAO, 1968; TANG, 1978; LI \& Thompson, 1981; McCawley, 1992), Chinese adjectives are a type of verbs, because they share syntactic properties with verbs. The most important similarity between Chinese verbs and adjectives is that they both can function as predicates directly and independently; in other words, they can fill in the same syntactic slot in a sentence. We would assume that if they belong to the same form class, then they might also share the morphological properties; in other words, adjectives should have the same or similar morphological operations as verbs. One of the same operations for verbs and adjectives is A-not-A question operation, as illustrated in Table 9.

Table 9

A-not-A Operation in Chinese Verbs and Adjectives

\begin{tabular}{|l|l|l|l|l|}
\hline Type & Original form & A-not-A & Pinyin & Gloss \\
\hline $\mathrm{V}+\mathrm{O}$ & 睡觉 & 睡不睡觉 & shuijiao & To sleep or not \\
\hline $\mathrm{O}+\mathrm{V}$ & 步行 & 步不步行 & buxing & To walk or not \\
\hline $\mathrm{A}+\mathrm{A}$ & 美丽 & 美不美丽 & meili & To be beautiful or not \\
\hline $\mathrm{A}+\mathrm{V}$ & 好看 & 好不好看 & haokan & To be good-looking or not \\
\hline $\mathrm{V}+\mathrm{A}$ & 开阔 & 开不开阔 & kaikuo & To be wide or not \\
\hline $\mathrm{N}+\mathrm{A}$ & 笔直 & 笔不笔直 & bizhi & To be straight like pen or not \\
\hline $\mathrm{V}+\mathrm{N}$ & 超群 & 超不超群 & chaoqun & To be outstanding or not \\
\hline $\mathrm{A}+\mathrm{X}$ (suffix) & 粘乎 & 粘不粘乎 & nianhu & To be sticky or not \\
\hline
\end{tabular}

Packard (2000) argued that this operation applies to the left constituents of verbs, because native speakers construe the heads of the verbs are on the left side. This operation indeed applies to adjectives as shown in Table 9. 
In $[\mathrm{N}+\mathrm{A}],[\mathrm{V}+\mathrm{N}]$, and $[\mathrm{V}+\mathrm{A}]$ types of adjectives, the A-not-A question operation can still apply. This suggests that Chinese speakers take the first left element of the whole adjective word as a head even though it is not an adjective. This is the same as the verb compound 步行 buxing, “walk or not”. It can have an A-not-A operation on its head 步 bu “step", although it is a noun, not a verb. The reason is that the head of Chinese verbs is on the left. Through percolation, the form class of gestalt word determines the form classes of constituents of gestalt words. Therefore, Chinese speakers construe the left elements of the gestalt adjective words as adjectives.

However, it can also be argued that an adjective can be applied to A-not-A question operation is not because its head is on the left but because the rule of A-not-A question requires the first left constituent must be repeated no matter if it is a head or not. This issue will not be discussed in this paper.

\section{Conclusions}

This study investigated the headedness of Chinese adjectives and argued that the head of Chinese adjectives is more likely on the left than on the right. Statistically, Chinese adjectives may be two headed or the heads are "free to vary", but the ABB type of adjectives and syntactic reanalysis seem to suggest that the head should be on the left. This conclusion supports the Headedness Principle in Chinese. In addition, the author also argued that the ABB type of adjective reduplication is more likely to be a compounding process than a suffixation due to the fact that most BB parts of the adjectives still have concrete lexical meanings and many of them can be used freely as independent words. They may be in the process of grammaticalization, and are becoming more and more a suffix. However, even if they are suffixes, they do not change the form classes of the adjective words and thus they are not heads; thus the head of Chinese adjectives still tends to be on the left hand of the adjective words.

\section{References}

CAO, R. F. (1995). 普通话ABB式形容词的定量分析 (The quantitative analysis of ABB adjectives in Mandarin Chinese). 语文 研究, 3, 22-25.

Ceccagno, A., \& Basciano, B. (2006). Classification, structure and headedness of Chinese compounds. Lingue E Linguaggio, 2, 233-260.

Ceccagno, A., \& Basciano, B. (2007). Compound headedness in Chinese: An analysis of neologisms. Morphology, 2, $207-231$.

CHAO, Y. R. (1968). A grammar of spoken Chinese. Berkeley: University of California Press.

Haugen, J. D. (2008). Reduplication in compounding contexts: Morphological doubling vs. correspondence. Paper presented at NELS 39, Cornell University, Ithaca, NY.

HUANG, S. F. (1998). Chinese as a headless language in compounding morphology. In J. L. Packard (Ed.), New approaches to Chinese word formation (p. 261). Berlin, New York: Mouton de Gruyter.

LI, C. N., \& Thompson, S. A. (1981). Mandarin Chinese: A functional reference grammar. Berkeley: University of California Press. Lieber, R. (1981). On the organization of the lexicon. Bloomington: Indiana University Linguistics Club.

Lieber, R. (1992). Deconstructing morphology: Word formation in syntactic theory. Chicago: The University of Chicago Press.

LV, S. X. (1996). 现代汉语八百词 (Eight hundred words in modern Chinese) (pp. 314-321). Beijing: The Commercial Press.

Marantz, A. (1982). ReReduplication. Linguistic Inquiry, 13, 435-482.

McCarthy, J., \& Prince A. (1986). Prosodic morphology (MS, University of Massachusetts, Amherst, and Brandeis University, Waltham, MA).

McCawley, J. D. (1992). Justifying part-of-speech assignments in Mandarin Chinese. Journal of Chinese Linguistics, 20(2), 211-245.

Packard, J. L. (2000). The morphology of Chinese: A linguistic and cognitive approach (p. 65). Cambridge: Cambridge University Press. 
Scalise, S. (1988). The notion of "head" in morphology. In G. Booij \& J. van Marle (Eds.), Yearbook of morphology (pp. 229-245). Dordrecht: Kluwer.

Sproat, R. (1998). Review of Packard: New approaches to Chinese word formation. In G. Booij \& J. van Marle (Eds.), Yearbook of morphology (pp. 289-309). Boston, Dordrecht, and London: Kluwer Academic Publishers.

Starosta, S., Kuiper, K., Ng, S., \& WU, Z. (1998). On defining the Chinese compound word: Headedness in Chinese compounding and Chinese V-R compounds. New approaches to Chinese word formation: Morphology, phonology and lexicon in modern and ancient Chinese. Berlin and New York: Mouton e Gruyter.

TANG, T. C. (1978). Collections of Mandarin grammar study (pp. 161-167). Taipei: Taiwan Xuesheng Shuju.

Williams, E. (1981). On the notions lexically related and head of a word. Linguistic Inquiry, 12, 245-274.

ZHANG, D. (2005). 汉语中ABB型状态形容词的构成分析 (The analysis of ABB adjective formation in Chinese). 沈阳农业 大学学报 (社会科学版)，7(1), 124-126.

ZHU, K. Y. (1994). 中缀说略 (Aspects of infixes). 贵州师范大学学报(社科版), 4, 26-28.

现代汉语词典 (Modern Chinese Dictionary). (1996). Beijing: Commercial Press. 